\title{
The differences of pulse on the training day based on hours sleep
}

\author{
Yohanes Touvan Juni Samodra \\ Universitas Tanjungpura, Indonesia
}

Received: 08 December 2020; Accepted 22 January 2021; Published 22 February 2021

Ed 2021; 6(1): 76-85

\begin{abstract}
The quality of rest will give a good result for the adaptation of the exercise. Exercise is carried out, so that physical condition has improved. The pulse rate is an indicator that can be used to see the process or results of exercise adaptation. If the waking pulse rate is still high, it can be assumed that time is still needed to rest. This study aims to determine the difference in the pulse rate of waking up from samples who sleeps more than 6 hours and 6 hours below. The research is carried out by experiment. The sample is given $75 \%$ weight training with 12 tools for 12 meetings. Pulse measurement is done independently before and upon waking. Data are analyzed using the T-test. Based on the results, it is reported that 25 people are trying to rest 6 hours down and 47 times resting above 6 hours. Based on the T-test analysis, it is found that there is a significant difference between respondents who sleep less than 6 hours and more than 6 hours with a significance of .002 with a mean of -0.8 for those who rested 6 hours and less and 4.6 for those who sleep more than 6 hours. This research can be replicated by considering several variables related to the acceleration of recovery, including Vo2Max, blood HB, and it is necessary to consider the differences between sons and daughters.
\end{abstract}

Keywords: Pulse; practice; sleep hours

d.

https://doi.org/10.25299/sportarea.2021.vol6(1).5996

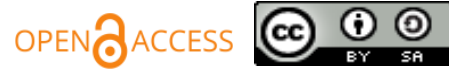

Copyright $\odot 2021$ Yohanes Touvan Juni Samodra

Corresponding author: Yohanes Touvan Juni Samodra, Physical Education Health and Recreation, Universitas Tanjungpura, Pontianak, Kalimantan Barat, Indonesia

Email: tovan@fkip.untan.ac.id

How To Cite: Samodra, Y. T. J. (2021). The differences of pulse on the day of training based on hours sleep. Journal Sport Area, 6(1), 76-85. https://doi.org/10.25299/sportarea.2021.vol6(1).5996

\section{INTRODUCTION}

Exercise intensity is a very important part of training. Exercise intensity is the percentage of a person can cope with the load in a certain time (Buzzichelli, 2019), with an intensity division of less than 50\% low, $50 \%-70 \%$ medium, $70 \%-80 \%$ medium weight, $80 \%-90 \%$ weight, $90 \%-100 \%$, maximum and above 100 supermaximal (Buzzichelli, 2019). The recommended exercise to achieve good results in recent times is of high intensity, review evidence shows moderate and high intensity exercise are more effective against cardiac systole (Clark et al., 2020), reduced risk of complications in obesity (Koh, Park, \& Carter, 2018), fitness, obesity and cardiorespiratory (Hay et al., 2016) and increased VO2max (Zouhal et al., 2020), then there is an influence on people in relation to body image, to improve body composition (Wewege, van den Berg, Ward, \& Keech, 2017; Álvarez et al., 2018), those who are overweight can be treated with high intensity (de Lira et al., 2017), insulin performance body fat composition (Zhang et al., 2017; Türk et al., 2017), keep the heart in shape (Chuensiri, Suksom, \& Tanaka, 2018; Türk et al., 2017; Dias et al., 2018).

Next is a study of high intensity exercise. A study concludes that high-intensity aerobic exercise has a positive effect on the dilatation capacity of blood vessels and an increase in the ability of systole pressure 
(Chrysohoou et al., 2015). That high-intensity exercise actually disturbs people with high blood pressure early (Gkaliagkousi, Gavriilaki, Nikolaidou, Triantafyllou, \& Douma, 2014). Aerobic exercise at a dose of $60-80 \%$ for 12 weeks with 5 exercises per week to significantly increase Vo2-max, muscle strength and endurance (Kang, Kim, \& Ko, 2016). Some of these studies provide information that high intensity is beneficial, but some are actually annoying in people with high blood pressure. At least high-intensity exercise is ultimately beneficial for muscle and blood vessel endurance.

In its development, a person's health is determined by the quality of blood vessels. This is evidenced by research that there is a relationship between sleep quality and the occurrence of artheoslerosis (Kadoya, \& Koyama, 2019). The stiffness of the blood vessels can cause serious problems (American Heart Association, 2019), the occurrence of pulse wave velocity (PWV) (Petersen, Blanch, Keogh, \& Clifton, 2015) and conversely people who are obese also cause stiffness of blood vessels (Maeda et al., 2015). Other factors that cause stiffness of blood vessels besides obesity are age and smoking (Doonan et al., 2011). A smoker when doing exercises will experience excessive fatigue at various intensities, as well as optimization of VO2max (Mendonca, Pereira, \& Fernhall, 2011), and there is an increase in resting pulse when compared to nonsmokers (Doonan et al., 2011).

Research evidence suggests that aerobic exercise reduces blood vessel stiffness (Montero, Vinet, \& Roberts, 2015) and increases the flexibility of blood vessels (Ashor, Lara, Siervo, Celis-Morales, \& Mathers, 2014). If the blood vessels are not stiff, their work will be more efficient, this is indicated by a decrease in pulse rate per minute. The results show that 3 months of aerobic exercise improved the quality of life with an increase in Vo2max capacity (Van Craenenbroeck et al., 2015), stretching for 40 minutes occurs in response to the arteries even though it doesn't last long and will return to its original position (Yamato et al., 2016). Thus, this gives an idea that aerobic exercise and stretching are very necessary for smooth blood flow.

Subsequent research provides evidence that yoga practice every morning for 12 weeks is effective in reducing arterial stiffness provided that during exercise the pulse must be in an increased condition (Patil, Aithala, \& Das, 2015). The results also provide information that yoga significantly reduces sympathetic nerve activity and improves endhotel function (Patil et al., 2015). Soothing music for the benefit of lowering the pulse after exercise does not have a significant effect (Tan, Tengah, Nee, \& Fredericks, 2014).

Next, the problem in this study is adaptation as an effect of exercise. Each exercise will have the function of stressing the physiology of the body. Each dose of exercise has its own effect. Research provides evidence that exercise will increase the amount of oxygen used in the blood (Anupama et al., 2016). The use of this amount of oxygen is characterized by an increase in the number of pulses during exercise. There is a greater increase in pulse rate among people who are heavier than normal (Bunsawat et al., 2017). High intensity aerobic exercise for 8 weeks significantly increased VO2max and decreased systole significantly in the experimental group (Ranadive et al., 2016). This study provides an understanding that, with exercise, the pulse will increase in tune with the increase in the amount of energy required. There is a comparison that people who are overweight, there will be a more increase in pulse, this is due to the more need to supply energy to the very end of the body.

It is found that the decrease in arterial quality is not affected by either dose (Shibata et al., 2018), what matters is the amount of exercise in a week. Based on the findings of this study, regular and continuous exercise is needed to maintain blood vessel fitness. Weight training 70-80\% affects arterial stiffness (Okamoto, Kobayashi, \& Sakamaki-Sunaga, 2017). Exercise can be recommended to lower blood pressure (Thompson et al., 2019).

There is a new training model, namely by blocking the flow of blood, there will be a bigger contraction if this method is used (Kjeldsen, Næss-Schmidt, Hansen, Nielsen, \& Stubbs, 2019), this exercise is done by tying the muscles, it is uncomfortable, is more painful and has a higher level of fatigue (Kjeldsen et al., 2019). Based on research exercise improves arterial blood vessel function even without weight loss (Maeda et al., 2015). Exercising with a 50\% load for 10 weeks twice a week is found to have an effect on a decrease in pulse rate and an increase in lift up to a maximum of 1 time (Okamoto, Masuhara, \& Ikuta, 2011) and increase the ability of blood vessels. The point of this study is that with training there will be an increase in 
pulse rate, normal people with excess body weight will have a different effect on overcoming the training load that is represented in the intensity of the exercise. The same exercise intensity with different body weight will have a different response. It is stated that people who are obese will have an increased pulse rate that is more than normal people. Expressed by (Thompson et al., 2019); exercise can lower blood pressure, (Ranadive et al., 2016), there is a decrease in systole (Maeda et al., 2015) exercise can lower your pulse. In conclusion, when doing exercises, there will be an increase in pulse rate, but after passing time, with a certain dose there will be a decrease in pulse rate. The decrease in the pulse rate is an indicator that there has been an adaptation and the work of the heart is becoming more efficient, so that one beat will be more efficient in delivering blood throughout the body.

This study tries to dig up information by conducting experiments on the relationship between a decrease in the pulse rate of exercise before going to bed and waking up, with the holding of weight training with a dose of $75 \%$. This is interesting because the person who exercises will try to overcome the load (75\%) so, the work of the heart and muscles will simultaneously overcome the load. The pulse will go up when doing the exercise, then after a night's rest, if the time required is sufficient, logically the pulse will decrease. This recovery process takes time. Thus, this process is very complicated and needs proof. The time required to perform recovery is a separate consideration. So that the amount of sleep time is one of the concerns. Normal people need a minimum of 6 hours of rest, so this period is the time limit for differentiating as an analytical study.

\section{METHODS}

This research is an experimental research. The study is conducted by providing $75 \%$ weight training treatment, followed by pulse recording before bedtime, sleep duration and after sleep for 12 meetings (Frankel, Wallen, \& Hyun, 2011). This research includes the time series. The aim of experimental research is to prove the importance of the number of hours of rest needed when doing exercises. The hope is that this can be an important insight in training activities for sports achievements. The research was carried out in October 2020 at the Sports Science Department Lab, Teacher Training and Education Faculty, Tanjungpura University, Pontianak. The research subjects are sports coaching students totaling 7 students, 3 girls, and 4 boys.

The research procedure is carried out in several stages. First, a test on the maximum ability of each student is carried out for 12 stations. The test is looking for the ability of 1 maximum repetition (Buzzichelli, 2019; Himano, Raemer, Piering, \& Olek, 2006), except for sit up and crunches (maximum reptisi in 1 minute). The names of the tools used are leg press, pull down, back up, standing rowing, leg extension, butterfly, sit up, chest press, tricep ectention, claft raise, leg curl, and crunch.

The second specifies a $75 \%$ dose as treated for exercise. The treatment is carried out for 12 meetings, 3 times a week, 3 sets of each exercise. Repetitions performe between 12-16 times per tool as quickly as possible. The time for switching between tools is 10-15 seconds with rest periods between sets of 3-4 minutes. Exercises are carried out Monday, Wednesday, and Friday nights starting at 6:15 P.M. to finish. Exercise begins with a stationary bike for 15-20 minutes, stretching, checking your pulse, followed by circuit weight training.

Pulse measurement is carried out independently before and after sleeping on the day after doing the exercise. Pulse measurement is carried out for 1 minute (Nurdin, Nur, Syahrir, Fadlan, \& Musyawira, 2015). The pulse that is felt for measurement is the pulse in the neck. So that the data obtained is the number of pulse beats counted in 1 minute. The data are analyzed using the $\mathrm{T}$ test before the $\mathrm{T}$ test is first tested for the normality of the data.

\section{RESULTS AND DISCUSSIONS}

The results of the analysis of the differences in resting pulse rates based on the number of hours of sleep up to 6 hours and less than 6 hours. 
Table 1. Average Time Difference

\begin{tabular}{ccc}
\hline Sleep & Amount of data & Average Difference in Pulse \\
\hline Up to 6 hours & 25 & -0.8 \\
More than 6 hours & 47 & 4,65 \\
\hline
\end{tabular}

The research subjects do the exercise 3 times per week, with an exercise dose of $75 \%$. The day after the exercise before going to bed measurements of the pulse, as well as when you wake up. The number of hours of sleep that has occurred is recorded. So that it is classified there are 25 incidents of sleep up to the limit of 6 hours and 47 incidents of sleeping more than 6 hours. The number of hours of sleep is then seen the difference between the pulse training before and when you wake up. It turns out that on average, the less sleep, the difference in pulse before and at waking time tends to be negative -0.8 the rate or pulse of waking up is higher than before bedtime. Conversely, if the number of hours of sleep exceeds 6 hours there is a positive difference in pulse rates of 4.65 beats. This means that the more hours you sleep, the pulse for waking up is lower than the pulse before going to sleep.

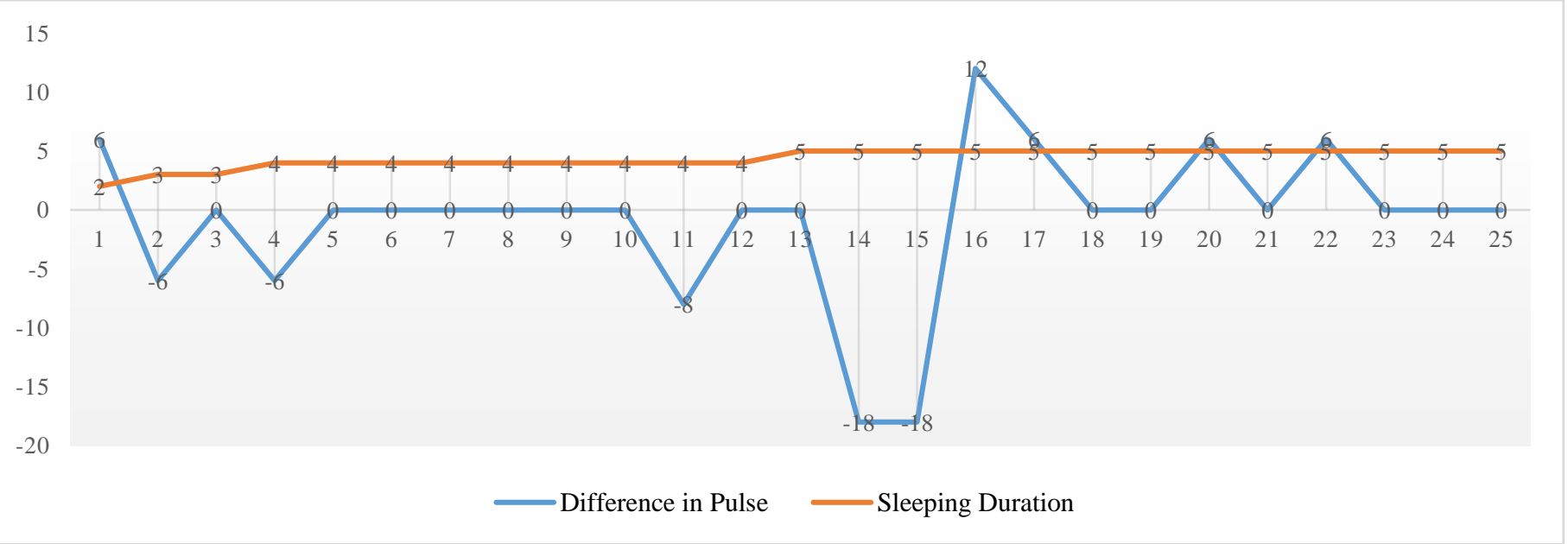

Figure 1. Number of hours of sleep and difference in sleep pulse up to 6 hours

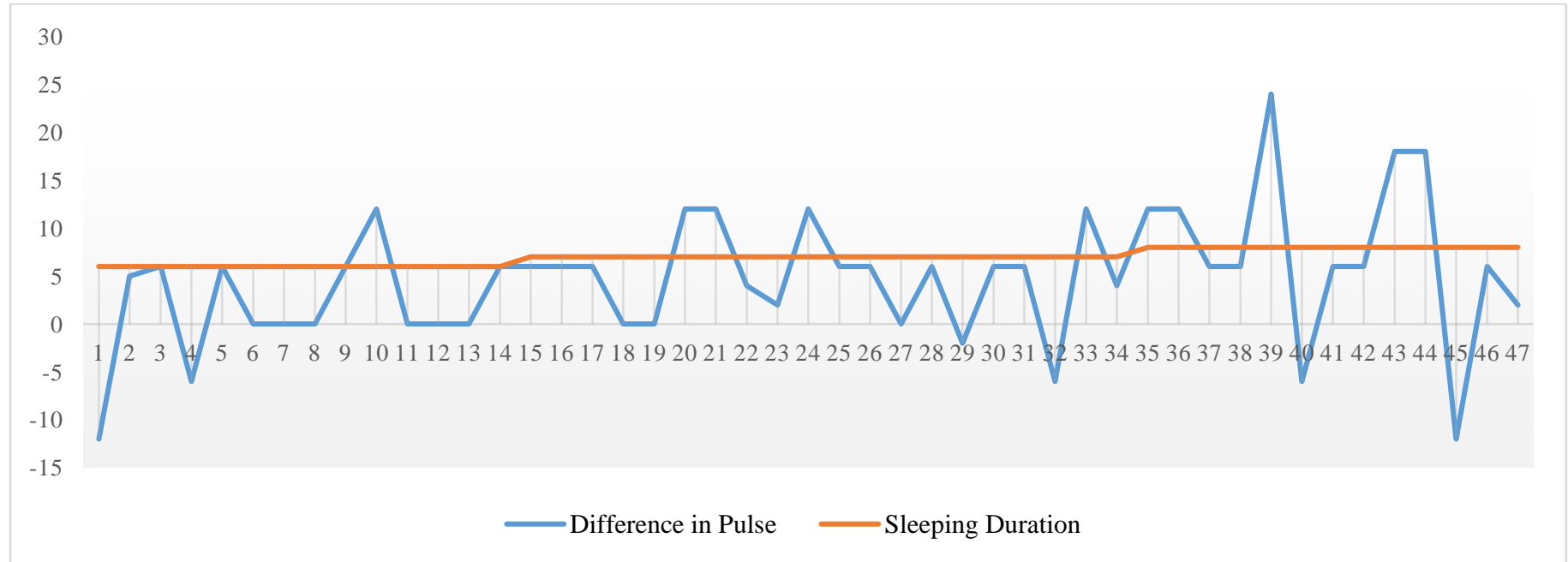

Figure 2. Hours of sleep and difference in sleep pulse of more than 6 hours

Figures 1 and 2 provide a clearer explanation that the longer the time spends sleeping by the person, so it is the greater of the difference in pulse before and after waking up. Furthermore, to prove whether the difference in pulse before and after this is significantly different, then the $\mathrm{T}$ test is carried out. The $\mathrm{T}$ test results obtain the following results: 
Table 2. Test Results for Difference in Pulse Based on Duration of Sleep

\begin{tabular}{lrlcc}
\hline & & & Equal variances assumed & Equal variances not assumed \\
\hline $\begin{array}{l}\text { Levene's Test for } \\
\text { Equality }\end{array}$ & of & Sig. & .640 & \\
Variances & & $\mathrm{t}$ & .426 & -3.252 \\
& & & -3.191 & 51.779 \\
t-test for Equality of & $\mathrm{df}$ & & 70 & .002 \\
Means & Sig. (2-tailed) & & .002 & -5.45957 \\
& Mean Difference & & -5.45957 & 1.67885 \\
& Std. Error Difference & Lower & 1.71107 & -8.82878 \\
& & Upper & -8.87219 & -2.09037 \\
\hline
\end{tabular}

Based on the table, it is found that the Levene's Test for Equality of Variances with a significance of 0.426 , the data is declared normal. Next, the significance value of the T test is 0.002 , this states that there is a significant difference in hours of sleep on changes in resting pulse. Research provides strong evidence that more than 6 hours of rest will have a good effect on recovery. This is supported by data from table 1 . The findings of this study provide a message that rest as indicated by the number of hours of sleep is very important for the recovery process. This rest hour for normal people is usually 6 hours. The findings in this study require more than 6 hours to obtain good recovery results. This rest will provide an opportunity for the body's physiology to regenerate.

Various studies have shown that exercise will affect your pulse and blood pressure, it is evident that the arteries will be more flexible after weight training (Au, Oikawa, Morton, MacDonald, \& Phillips, 2017). A researcher recommends doing weight training in order to get a good adaptation of blood vessel function (Au et al., 2017). Aerobic exercise and weight training have a significant effect on diastolic pressure (Zhang et al., 2018).

Exercise for 4 weeks at a dose of $65 \% 3$ times per week was found to have an effect on lowering blood pressure (Goldberg, Boutcher, \& Boutcher, 2012). It turns out that interval training is more effective for people with heart rehabilitation (Freyssin, Verkindt, Prieur, Benaich, Maunier, \& Blanc, 2012) with a training dose of 3 training sessions 12 reps for 30 seconds with a rest of 60 seconds. The number of pulses and blood pressure was correlated (Sikiru \& Okoye, 2013). Exercise of moderate intensity can help in hypertension management and prevention programs (Sikiru \& Okoye, 2013). Both moderate intensity continuous aerobic exercise and high intensity aerobic interval training have an effect on increasing dilated flow of blood vessels (Siasos et al., 2016). There is a conclusion that people who exercise 4-5 times a week maintain the quality of the arteries in other words, there is good maintenance of the arteries (Shibata et al., 2018).

The results of the research that occurred give a strong message that, exercise will affect the quality of blood vessels. In essence, increasing activity when exercising will have an effect on the work of blood vessels. The performance of these blood vessels is more flexible, less rigid, and smoother. With the smoother performance of the blood vessels, the supply and process of bringing the remaining combustion to be reprocessed or disposed of will be smoother. In particular, exercise provides evidence that there will be a decrease in the resting pulse rate. It has been done a lot. Exercise with a dose of 70-80\% with the sequence of weight training after aerobic dose training, it turns out that there is an adaptation to a decrease in pulse (Shiotsu, Watanabe, Tujii, \& Yanagita, 2018). Exercise for 12 weeks with aerobic intensity was found to have an effect on decreasing resting pulse rates (Osbak et al., 2011; Huang, Wang, Deng, She, \& Wu, 2016). Weight loss of $8 \%$ from initial body weight through diet and lifestyle changes was found to improve pulse rhythm (Petersen et al., 2015). Aerobic exercise at a dose of $60-80 \%$ for 12 weeks with 5 exercises per week was found to significantly reduce resting pulse rates. The following information illustrates that prolonged aerobic exercise also has a greater effect on increasing Vo2max (Huang et al., 2016). Based on the results of research and relevant research studies, it provides evidence that rest is very important. This study provides exercise intervention with a dose of $75 \%$, it turns out that the rest factor determines recovery. 
This research is conducted on students, based on the results of the research it can provide an important information foundation, that the number of hours of rest will provide physiological opportunities for regeneration. The results of this regeneration can be seen from the pulse rate reduction indicator. If the pulse is still high it can be assumed that there is less rest. Furthermore, for people who do exercises with a $75 \%$ load, at least a break of more than 6 hours is needed.

\section{CONCLUSION}

Exercise with an intensity of $75 \%$ associated with resting pulse in this study provides evidence that the number of hours rest determines recovery. There is a significant difference between the pulse before going to sleep and waking up between those who sleeps up to 6 hours and more than 6 hours. Exercise will increase your pulse. The exercise adaptation process will occur when the rest hours are fulfilled. The longer the time spent resting can be seen from the change in the pulse rate of waking up. Limitations in this study, firstly, still not considering the activity factor outside of exercise on days other than training days. Second, it has not included macro nutrition input as a variable for energy fulfillment and adaptation interests. Recommendations for further research need to be clearly distinguished between men and women with a larger sample. Needing an initial test of fitness status (especially Vo2Max), this variable may be able to differentiate the time it takes to recover. Third, it is necessary to look at the HB level, it is known that HB in the blood affects the process of transporting $\mathrm{O} 2$ and $\mathrm{CO} 2$. It is necessary to consider the record of fluid intake. This variable is a very important variable in relation to the function of the thermoregulator and the transport system.

\section{REFERENCES}

Álvarez, C., Ramírez-Campillo, R., Ramírez-Vélez, R., Martínez, C., Castro-Sepúlveda, M., AlonsoMartínez, A., \& Izquierdo, M. (2018). Metabolic effects of resistance or high-intensity interval training among glycemic control-nonresponsive children with insulin resistance. International Journal of Obesity. 42(1), 79-87. https://doi.org/10.1038/ijo.2017.177

American Heart Association. (2019). Changes You Can Make to Manage High Blood Pressure | American Heart Association. Health Topics.

Anupama, N., Kini, R. D., Vishnu Sharma, M., Bhagyalaksmi, K., Nayanatara, A. K., Shetty, S., ... Anshuman. (2016). Effect of exercise on oxygen saturation and heart rate in healthy young adults of different body mass index. Research Journal of Pharmaceutical, Biological and Chemical Sciences, $7(5), 594-597$.

Ashor, A. W., Lara, J., Siervo, M., Celis-Morales, C., \& Mathers, J. C. (2014). Effects of exercise modalities on arterial stiffness and wave reflection: A systematic review and meta-analysis of randomized controlled trials. PLoS ONE, 9(10), e110034. https://doi.org/10.1371/journal.pone.0110034

Au, J. S., Oikawa, S. Y., Morton, R. W., MacDonald, M. J., \& Phillips, S. M. (2017). Arterial Stiffness Is Reduced Regardless of Resistance Training Load in Young Men. Medicine and Science in Sports and Exercise, 49, 342-349. https://doi.org/10.1249/MSS.0000000000001106

Bunsawat, K., Ranadive, S. M., Lane-Cordova, A. D., Yan, H., Kappus, R. M., Fernhall, B., \& Baynard, T. (2017). The effect of acute maximal exercise on postexercise hemodynamics and central arterial stiffness in obese and normal-weight individuals. Physiological Reports, 5(7), e132. https://doi.org/10.14814/phy2.13226

Buzzichelli, T. O. B. and C. A. (2019). Periodization : theory and methodology of training. (J. M. G. A. A. C. G. W. Earle, Ed.) (Sixth Edit). United States of America: Human Kinetics. 
Chrysohoou, C., Angelis, A., Tsitsinakis, G., Spetsioti, S., Nasis, I., Tsiachris, D., ... Dimitris, T. (2015). Cardiovascular effects of high-intensity interval aerobic training combined with strength exercise in patients with chronic heart failure. A randomized phase III clinical trial. International Journal of Cardiology, 20(179), 269-274. https://doi.org/10.1016/j.ijcard.2014.11.067

Chuensiri, N., Suksom, D., \& Tanaka, H. (2018). Effects of High-Intensity Intermittent Training on Vascular Function in Obese Preadolescent Boys. Childhood Obesity. https://doi.org/10.1089/chi.2017.0024

Clark, T., Morey, R., Jones, M. D., Marcos, L., Ristov, M., Ram, A., ... Keech, A. (2020). High-intensity interval training for reducing blood pressure: a randomized trial vs. moderate-intensity continuous training in males with overweight or obesity. Hypertension Research, 40(35), 396-403. https://doi.org/10.1038/s41440-019-0392-6

de Lira, C. T. C., dos Santos, M. A. M., Gomes, P. P., Fidelix, Y. L., dos Santos, A. C. O., Tenório, T. R. S., ... do Prado, W. L. (2017). Aerobic training performed at ventilatory threshold improves liver enzymes and lipid profile related to non-alcoholic fatty liver disease in adolescents with obesity. Nutrition and Health, 23(4), 281-288. https://doi.org/10.1177/0260106017720350

Dias, K. A., Ingul, C. B., Tjønna, A. E., Keating, S. E., Gomersall, S. R., Follestad, T., ... Coombes, J. S. (2018). Effect of High-Intensity Interval Training on Fitness, Fat Mass and Cardiometabolic Biomarkers in Children with Obesity: A Randomised Controlled Trial. Sports Medicine. https://doi.org/10.1007/s40279-017-0777-0

Doonan, R. J., Scheffler, P., Yu, A., Egiziano, G., Mutter, A., Bacon, S., ... Daskalopoulou, S. S. (2011). Altered arterial stiffness and subendocardial viability ratio in young healthy light smokers after acute exercise. PLoS ONE, 6(10), e26151. https://doi.org/10.1371/journal.pone.0026151

Frankel, J. R., Wallen, N. E. \& Hyun, H. H. (2011). How to Design and Evaluate Research in Education (8th Edition). (S. Kiefer, Ed.), Boston: McGraw-Hill. (8th ed.). New York: McGraw-Hill Education.

Freyssin, C., Verkindt, C., Prieur, F., Benaich, P., Maunier, S., \& Blanc, P. (2012). Cardiac rehabilitation in chronic heart failure: effect of an 8-week, high-intensity interval training versus continuous training. Archives of physical medicine and rehabilitation, 93(8), 1359-1364. https://doi.org/10.1016/j.apmr.2012.03.007

Gkaliagkousi, E., Gavriilaki, E., Nikolaidou, B., Triantafyllou, G., \& Douma, S. (2014). Exercise-Induced Pulse Wave Velocity Changes in Untreated Patients With Essential Hypertension: The Effect of an Angiotensin Receptor Antagonist. Journal of Clinical Hypertension, 16(7), 482-487. https://doi.org/10.1111/jch.12340

Goldberg, M. J., Boutcher, S. H., \& Boutcher, Y. N. (2012). The effect of 4 weeks of aerobic exercise on vascular and baroreflex function of young men with a family history of hypertension. Journal of Human Hypertension, 26, 644-649. https://doi.org/10.1038/jhh.2011.95

Hay, J., Wittmeier, K., MacIntosh, A., Wicklow, B., Duhamel, T., Sellers, E., ... McGavock, J. (2016). Physical activity intensity and type 2 diabetes risk in overweight youth: A randomized trial. International Journal of Obesity, 40(4), 607-614. https://doi.org/10.1038/ijo.2015.241

Himano, T. O. S., Raemer, W. I. J. K., Piering, B. A. A. S., \& Olek, J. E. F. F. S. V. (2006). Relationship between the number of repetitions and selected percentages of one repetition maximum in free weight exercises in trained and untrained men, 20(4), 819-823. 
Huang, C., Wang, J., Deng, S., She, Q., \& Wu, L. (2016). The effects of aerobic endurance exercise on pulse wave velocity and intima media thickness in adults: A systematic review and meta-analysis. Scandinavian Journal of Medicine and Science in Sports, 26(5), 478-487. https://doi.org/10.1111/sms.12495

Kadoya, M., \& Koyama, H. (2019). Sleep, Autonomic Nervous Function and Atherosclerosis. International Journal of Molecular Sciences, 20(4), 794. https://doi.org/10.3390/ijms20040794

Kang, S. J., Kim, E. H., \& Ko, K. J. (2016). Effects of aerobic exercise on the resting heart rate, physical fitness, and arterial stiffness of female patients with metabolic syndrome. Journal of Physical Therapy Science, 28(6), 1764-1768. https://doi.org/10.1589/jpts.28.1764

Kjeldsen, S. S., Næss-Schmidt, E. T., Hansen, G. M., Nielsen, J. F., \& Stubbs, P. W. (2019). Neuromuscular effects of dorsiflexor training with and without blood flow restriction. Heliyon, 5(8), e02341. https://doi.org/10.1016/j.heliyon.2019.e02341

Koh, Y., Park, J., \& Carter, R. (2018). Oxidized Low-Density Lipoprotein and Cell Adhesion Molecules Following Exercise Training. International Journal of Sports Medicine, 39(2), 83-88. https://doi.org/10.1055/s-0043-118848

Maeda, S., Zempo-Miyaki, A., Sasai, H., Tsujimoto, T., So, R., \& Tanaka, K. (2015). Lifestyle modification decreases arterial stiffness in overweight and obese men: Dietary modification vs. exercise training. International Journal of Sport Nutrition and Exercise Metabolism, 25(1), 69-77. https://doi.org/10.1123/ijsnem.2013-0107

Mendonca, G. V., Pereira, F. D., \& Fernhall, B. (2011). Effects of cigarette smoking on cardiac autonomic function during dynamic exercise. Journal of Sports Sciences, 29(9), 879-86. https://doi.org/10.1080/02640414.2011.572991

Montero, D., Vinet, A., \& Roberts, C. K. (2015). Effect of combined aerobic and resistance training versus aerobic training on arterial stiffness. International Journal of Cardiology, 15(178), 69-76. https://doi.org/10.1016/j.ijcard.2014.10.147

Nurdin, M., Nur, A., Syahrir, S., Fadlan, D., \& Musyawira, F. H. (2015). Deteksi Denyut Jantung dengan Metode Sensor Pulsh Berbasis Ardiuno. In Prosiding Seminar Nasional Teknik Elektro \& Informatika. (pp. 201-206).

Okamoto, T., Kobayashi, R., \& Sakamaki-Sunaga, M. (2017). Effect of Resistance Exercise on Arterial Stiffness during the Follicular and Luteal Phases of the Menstrual Cycle. International Journal of Sports Medicine, 35(8). 347-352. https://doi.org/10.1055/s-0043-101377

Okamoto, T., Masuhara, M., \& Ikuta, K. (2011). Effect of low-intensity resistance training on arterial function. European Journal of Applied Physiology, 111(5), 743-8. https://doi.org/10.1007/s00421-010$1702-5$

Osbak, P. S., Mourier, M., Kjaer, A., Henriksen, J. H., Kofoed, K. F., \& Jensen, G. B. (2011). A randomized study of the effects of exercise training on patients with atrial fibrillation. American Heart Journal, 162(6), 1080-1087. https://doi.org/10.1016/j.ahj.2011.09.013

Patil, S. G., Aithala, M. R., \& Das, K. K. (2015). Effect of yoga on arterial stiffness in elderly subjects with increased pulse pressure: A randomized controlled study. Complementary Therapies in Medicine, 23(4). 562-569. https://doi.org/10.1016/j.ctim.2015.06.002 
Petersen, K. S., Blanch, N., Keogh, J. B., \& Clifton, P. M. (2015). Effect of weight loss on pulse wave velocity: Systematic review and meta-analysis. Arteriosclerosis, Thrombosis, and Vascular Biology, 35(1), 243-252. https://doi.org/10.1161/ATVBAHA.114.304798

Ranadive, S. M., Yan, H., Lane, A. D., Kappus, R. M., Cook, M. D., Sun, P., ... Fernhall, B. (2016). Aerobic exercise training and arterial changes in african americans versus caucasians. Medicine and Science in Sports and Exercise, 48(1), 90-97. https://doi.org/10.1249/MSS.0000000000000742

Shibata, S., Fujimoto, N., Hastings, J. L., Carrick-Ranson, G., Bhella, P. S., Hearon, C. M., \& Levine, B. D. (2018). The effect of lifelong exercise frequency on arterial stiffness. Journal of Physiology, 596(14), 2783-2795. https://doi.org/10.1113/JP275301

Shiotsu, Y., Watanabe, Y., Tujii, S., \& Yanagita, M. (2018). Effect of exercise ordning on arterial stiffness in older mener of combined aerobic and resistance trai. Experimental Gerontology, 1(111), 27-34. https://doi.org/10.1016/j.exger.2018.06.020

Siasos, G., Athanasiou, D., Terzis, G., Stasinaki, A., Oikonomou, E., Tsitkanou, S., ... Tousoulis, D. (2016). Acute effects of different types of aerobic exercise on endothelial function and arterial stiffness. European Journal of Preventive Cardiology, 24(14), 1565-72. https://doi.org/10.1177/2047487316647185

Sikiru, L., \& Okoye, G. C. (2013). Effect of interval training programme on pulse pressure in the management of hypertension: A randomized controlled trial. African Health Sciences, 13(3), 571-578. https://doi.org/10.4314/ahs.v13i3.7

Tan, F., Tengah, A., Nee, L. Y., \& Fredericks, S. (2014). A study of the effect of relaxing music on heart rate recovery after exercise among healthy students. Complementary Therapies in Clinical Practice, 20(2), 114-7. https://doi.org/10.1016/j.ctcp.2014.01.001

Thompson, S., Wiebe, N., Padwal, R. S., Gyenes, G., Headley, S. A. E., Radhakrishnan, J., \& Graham, M. (2019). The effect of exercise on blood pressure in chronic kidney disease: A systematic review and meta-analysis of randomized controlled trials. PLoS ONE, 14(2), e0211032. https://doi.org/10.1371/journal.pone.0211032

Türk, Y., Theel, W., Kasteleyn, M. J., Franssen, F. M. E., Hiemstra, P. S., Rudolphus, A., ... Braunstahl, G. J. (2017). High intensity training in obesity: a Meta-analysis. Obesity Science and Practice, 3(3), 258271. https://doi.org/10.1002/osp4.109

Van Craenenbroeck, A. H., Van Craenenbroeck, E. M., Van Ackeren, K., Vrints, C. J., Conraads, V. M., Verpooten, G. A., ... Couttenye, M. M. (2015). Effect of Moderate Aerobic Exercise Training on Endothelial Function and Arterial Stiffness in CKD Stages 3-4: A Randomized Controlled Trial. American Journal of Kidney Diseases, 66(2), 285-296. https://doi.org/10.1053/j.ajkd.2015.03.015

Wewege, M., van den Berg, R., Ward, R. E., \& Keech, A. (2017). The effects of high-intensity interval training vs. moderate-intensity continuous training on body composition in overweight and obese adults: a systematic review and meta-analysis. Obesity Reviews, 18(6), 635-646. https://doi.org/10.1111/obr.12532

Yamato, Y., Hasegawa, N., Sato, K., Hamaoka, T., Ogoh, S., \& Iemitsu, M. (2016). Acute Effect of Static Stretching Exercise on Arterial Stiffness in Healthy Young Adults. American Journal of Physical Medicine and Rehabilitation, 95(10), 764-770. https://doi.org/10.1097/PHM.0000000000000498 
Zhang, H., Tong, T. K., Qiu, W., Zhang, X., Zhou, S., Liu, Y., \& He, Y. (2017). Comparable Effects of High-Intensity Interval Training and Prolonged Continuous Exercise Training on Abdominal Visceral Fat Reduction in Obese Young Women. Journal of Diabetes Research, 2017, 1-10 https://doi.org/10.1155/2017/5071740

Zhang, Y., Qi, L., Xu, L., Sun, X., Liu, W., Zhou, S., ... Greenwald, S. E. (2018). Effects of exercise modalities on central hemodynamics, arterial stiffness and cardiac function in cardiovascular disease: Systematic review and meta-analysis of randomized controlled trials. PLoS ONE, 13(7), e0200829. https://doi.org/10.1371/journal.pone.0200829

Zouhal, H., Ben Abderrahman, A., Khodamoradi, A., Saeidi, A., Jayavel, A., Hackney, A. C., ... Jabbour, G. (2020). Effects of physical training on anthropometrics, physical and physiological capacities in individuals with obesity: A systematic review. Obesity Reviews, 21(9), e13039. https://doi.org/10.1111/obr.13039 